\title{
Polymer-Colloid Complexes Based on Cationic Imidazolium Amphiphile, Polyacrylic Acid and DNA Decamer
}

\author{
Darya A. Kuznetsova ${ }^{1}{ }^{\mathbb{D}}$, Dinar R. Gabdrakhmanov ${ }^{1}$, Denis M. Kuznetsov ${ }^{1}$, Svetlana S. Lukashenko ${ }^{1}$, \\ Valery M. Zakharov ${ }^{2}$, Anastasiia S. Sapunova ${ }^{1}$, Syumbelya K. Amerhanova ${ }^{1}$, Anna P. Lyubina ${ }^{1}$, \\ Alexandra D. Voloshina ${ }^{1}\left(\mathbb{D}\right.$, Diana V. Salakhieva ${ }^{3}$ and Lucia Ya. Zakharova ${ }^{1, *}$
}

1 FRC Kazan Scientific Center, Russian Academy of Sciences, Arbuzov Institute of Organic and Physical Chemistry, Arbuzov str. 8, 420088 Kazan, Russia; dashyna111@mail.ru (D.A.K.);

Nemezc1988@yandex.ru (D.R.G.); kuznetsov_denis91@mail.ru (D.M.K.); notass1@yandex.ru (S.S.L.); anastasiya.strobykina@iopc.ru (A.S.S.); syumbelya07@mail.ru (S.K.A.); aplyubina@gmail.com (A.P.L.); sobaka-1968@mail.ru (A.D.V.)

2 Kazan National Research Technological University, Karl Marx str., 68, 420015 Kazan, Russia; zakharov_vm@mail.ru

3 Institute of Fundamental Medicine and Biology, Kazan (Volga Region) Federal University, Kremlyovskaya St. 18, 420008 Kazan, Russia; DiVitSai@gmail.com

* Correspondence: luciaz@mail.ru; Tel.: +7-(843)-273-22-93

check for updates

Citation: Kuznetsova, D.A.; Gabdrakhmanov, D.R.; Kuznetsov, D.M.; Lukashenko, S.S.; Zakharov, V.M.; Sapunova, A.S.; Amerhanova, S.K.; Lyubina, A.P.; Voloshina, A.D.; Salakhieva, D.V.; et al.

Polymer-Colloid Complexes Based on Cationic Imidazolium Amphiphile, Polyacrylic Acid and DNA Decamer. Molecules 2021, 26, 2363. https:// doi.org/10.3390/molecules26082363

Academic Editors: Ramón G. Rubio and Tamar Greaves

Received: 2 February 2021

Accepted: 15 April 2021

Published: 19 April 2021

Publisher's Note: MDPI stays neutral with regard to jurisdictional claims in published maps and institutional affiliations.

Copyright: (c) 2021 by the authors. Licensee MDPI, Basel, Switzerland. This article is an open access article distributed under the terms and conditions of the Creative Commons Attribution (CC BY) license (https:/ / creativecommons.org/licenses/by/ $4.0 /)$.

\begin{abstract}
The solution behavior and physicochemical characteristics of polymer-colloid complexes based on cationic imidazolium amphiphile with a dodecyl tail (IA-12) and polyacrylic acid (PAA) or DNA decamer (oligonucleotide) were evaluated using tensiometry, conductometry, dynamic and electrophoretic light scattering and fluorescent spectroscopy and microscopy. It has been established that PAA addition to the surfactant system resulted in a ca. 200-fold decrease in the aggregation threshold of IA-12, with the hydrodynamic diameter of complexes ranging within 100-150 nm. Electrostatic forces are assumed to be the main driving force in the formation of IA-12/PAA complexes. Factors influencing the efficacy of the complexation of IA-12 with oligonucleotide were determined. The nonconventional mode of binding with the involvement of hydrophobic interactions and the intercalation mechanism is probably responsible for the IA-12/oligonucleotide complexation, and a minor contribution of electrostatic forces occurred. The latter was supported by zeta potential measurements and the gel electrophoresis technique, which demonstrated the low degree of charge neutralization of the complexes. Importantly, cellular uptake of the IA-12/oligonucleotide complex was confirmed by fluorescence microscopy and flow cytometry data on the example of M-HeLa cells. While single IA-12 samples exhibit roughly similar cytotoxicity, IA-12-oligonucleotide complexes show a selective effect toward M-HeLa cells $\left(\mathrm{IC}_{50} 1.1 \mu \mathrm{M}\right)$ compared to Chang liver cells $\left(\mathrm{IC}_{50}\right.$ $23.1 \mu \mathrm{M})$.
\end{abstract}

Keywords: imidazolium; amphiphile; polyacrylic acid; oligonucleotide; complexation

\section{Introduction}

Interactions between oppositely charged surfactants and synthetic polyelectrolytes are currently the focus of modern research [1-6]. This is mainly due to the possibility of the control of the properties of these systems by the variation of the chemical structure, ratio and concentration of components, molecular weight of the polymer, $\mathrm{pH}$ of the medium, temperature and ionic strength [7-9]. In addition, the fabrication of complexes can be mediated by different mechanisms, including the hydrophobic effect, van der Waals interactions and hydrogen bonding, with the contribution of dominating electrostatic interactions [10-13]. For these reasons, mixtures of polyelectrolytes and oppositely charged surfactants are characterized by the complicated behavior of solutions [14-16]. The addition of a high-molecular-weight component can change the aggregation thresholds of the 
system [17-20]. Moreover, the investigation of polymer-colloid systems allows simulating the interaction of cationic amphiphiles with natural polymers such as DNA, proteins and so on $[7,21-23]$. This is of importance in gene therapy [24,25] because the application of naked DNA molecules is complicated due to their huge size, the electrostatic repulsion between nucleotides and negatively charged cell membranes and the immune response observed [26]. Therefore, efficient transfection can be achieved using optimized carriers of polynucleotides, which allow compacting large DNA molecules and recharging them. This allows genetic material to be recognized by the cell $[27,28]$, pass through the cell membrane by the endocytosis mechanism [29] and receive protection from biodegradation. From this point of view, cationic surfactants are among the most prospective carriers [30-34], including those bearing an imidazolium moiety [35-38]. Imidazolium amphiphiles and DNA were documented to form sustainable nontoxic complexes that protect from enzymatic degradation and provide a charge density sufficient for DNA transport through the cell membrane [35]. Nonviral vectors based on the mixture of lipids and imidazolium amphiphiles were reported and were less effective than commercially available lipofectamine 2000; however, they had lower toxicity [36].

A brief literature overview makes it obvious that the fabrication of complexes based on amphiphiles and polyelectrolytes of various types is urgent. Nevertheless, despite the long-term study of these systems, there is little understanding of the factors influencing their functional activity. Much attention is paid to the interaction of cationic surfactants with anionic synthetic polyelectrolytes because they could simulate complexation between DNA and amphiphilic compounds. Unlike strong polyelectrolytes, weak polyelectrolytes demonstrate complicated and tunable solution behavior, which is controlled by the charge density of a polymer chain, which, in turn, is determined by the nature of macromolecules, concentration of charged additives, solution $\mathrm{pH}$, etc. For cationic surfactant-polyacrylic acid (PAA) binary systems, the critical ionization degree $\alpha_{c}$ should be taken into account. The theoretical value of $\alpha_{c}=0.35$ can be calculated based on Manning's counterion condensation theory [39]. Typically, electrostatic interactions prevail above $\alpha_{c}$, while the hydrophobic effect in combination with hydrogen binding contributes to complexation below $\alpha_{c}$. In accordance with the literature data [40], for surfactant-PAA systems, this threshold occurs at a $\mathrm{pH}$ of ca. 4.2 , beyond which the ionization degree markedly increases and electrostatically driven complexes are formed. Based on this information, it can be expected that these complexes show stimuli-responsive properties regulated by the solution $\mathrm{pH}$, concentration of components, ionic force, etc. This allows controlling the aggregation capacity and functional activity of the systems based on PAA. Therefore, this study is devoted to the elucidation of the self-assembling behavior and practical potentiality of the systems based on imidazolium amphiphiles bearing a dodecyl hydrophobic tail (IA-12, Figure 1) and two polyanions: (i) synthetic polyelectrolyte (polyacrylic acid, PAA, Figure 1) and (ii) a DNA decamer (oligonucleotide). For amphiphile/polyelectrolyte, systems their aggregation characteristics in aqueous solutions were quantified under different surfactant concentrations and fixed polyelectrolyte concentrations in accordance with an earlier protocol [41].

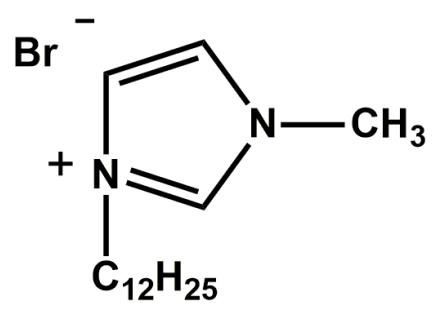

IA-12

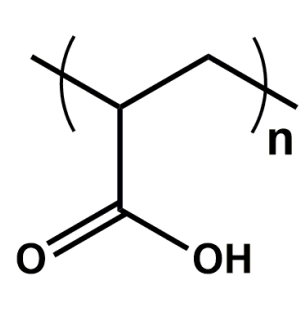

PAA

Figure 1. Chemical formulas of IA-12 and PAA studied in this report. 


\section{Results and Discussion}

\subsection{Mixed Systems Based on IA-12 and Polyacrylic Acid}

Binary IA-12/PAA systems were studied by the variation of the amphiphile concentration and three fixed concentrations of polyelectrolyte (1, 3 and $5 \mathrm{mM})$. In accordance with our previous reports $[41,42]$, a spontaneous $\mathrm{pH}$ of $\sim 4$ occurs under these conditions, which corresponds to an $\sim 8 \%$ degree of polyelectrolyte ionization. This means that PAA can be specified as a weak polyelectrolyte bearing a negative charge.

The first stage of the investigation was dedicated to the study of the aggregation properties of polymer-colloid systems. For this purpose, the surface tension technique was successfully used (Figure 2). Inflection points in surface-tension isotherms are usually taken as the critical micelle concentration (CMC) or the critical association concentration (CAC). Usually, there are more inflection points in the case of surfactant/polyelectrolyte systems in comparison with individual amphiphile solutions. This depends on various factors, including the nature and concentration of components, molecular weight of the polymer, geometry of the molecules, solution $\mathrm{pH}$, polyelectrolyte ionization degree, ionic strength, etc. It was shown that two inflection points were observed for the IA-12/PAA binary systems (Figure 2) regardless of the PAA concentration. The first inflection point $\left(\mathrm{CAC}_{1}\right.$, see arrows in Figure 2$)$ reflects the IA-12 concentration, at which the formation of amphiphile/polyelectrolyte complexes begins. The second inflection point $\left(\mathrm{CAC}_{2}\right.$, see arrows in Figure 2) corresponds to the saturation of macromolecules by amphiphile aggregates, after which individual IA-12 aggregates are formed. The CAC 1 and $C A C_{2}$ values obtained are compared with the CMC value for the individual IA-12 solutions [43] (Table 1). The addition of polyelectrolyte results in the formation of aggregates at a ca. 200 times lower amphiphile concentration $(0.046 \mathrm{mM})$ than in the case of individual amphiphile solutions $(9 \mathrm{mM})$. This effect is mostly expressed in the case of the lowest PAA concentration $(1 \mathrm{mM})$ and diminishes with an increase in the PAA concentration (Table 1). This fact is probably due to the distribution of amphiphiles between different macromolecules with an increase in their amount in solution.

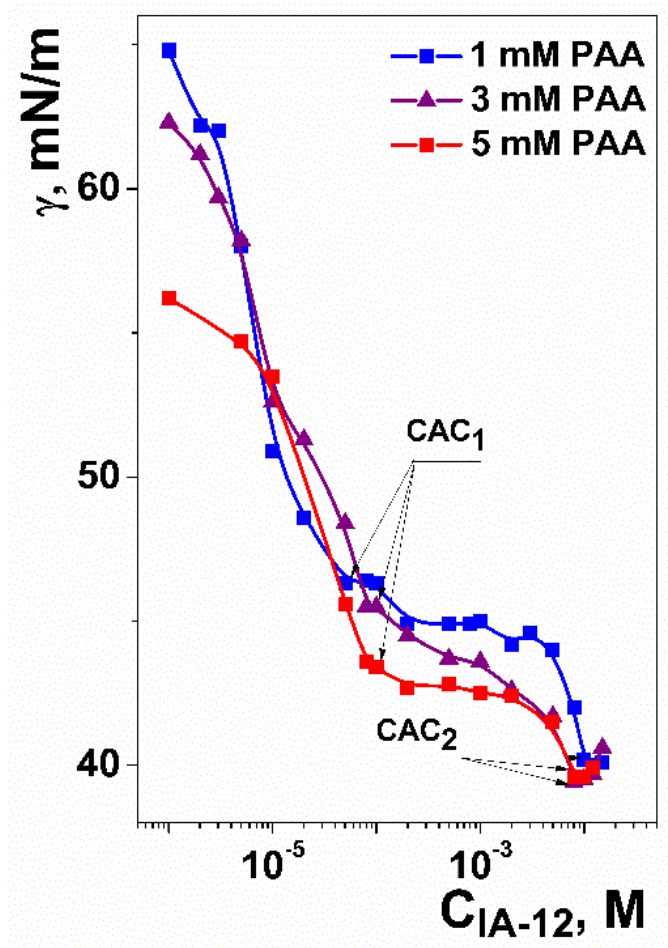

Figure 2. Surface tension isotherms for the IA-12/PAA binary systems at three fixed PAA concentrations; $\mathrm{pH}=4,25^{\circ} \mathrm{C}$. 
Table 1. Aggregation thresholds of the IA-12/PAA binary systems obtained by different physicochemical techniques.

\begin{tabular}{|c|c|c|c|c|}
\hline \multirow{3}{*}{$\mathrm{C}_{\text {PAA, }} \mathrm{mM}$} & \multicolumn{4}{|c|}{ Aggregation Thresholds (mM) } \\
\hline & \multicolumn{2}{|c|}{ Tensiometry } & \multirow{2}{*}{ Conductometry } & \multirow{2}{*}{ Fluorimetry } \\
\hline & $\mathrm{CAC}_{1}$ & $\mathrm{CAC}_{2}$ & & \\
\hline 0 & $9[43]$ & - & $10[43]$ & $9[43]$ \\
\hline 1 & 0.05 & 10.0 & 5 & 0.05 \\
\hline 3 & 0.08 & 9.0 & 4 & 0.05 \\
\hline 5 & 0.10 & 8.0 & 3.5 & 0.07 \\
\hline
\end{tabular}

To obtain reliable information on the aggregation behavior of IA-12/PAA binary systems, they were examined by two additional techniques: conductometry and fluorescence spectroscopy using pyrene as a probe (Figures S1 and S2, Supplementary Materials). This is motivated by the fact that these methods are based on different physical principles responsible for their accuracy while providing specific advantages and limitations. Tensiometry evaluates the structural behavior of the systems at the surface layer rather than in the bulk phase. Meanwhile, the interfacial characteristics of polyelectrolyte-surfactant systems can be modulated by different factors that are not related to the aggregation. At the same time, conductometry provides a valuable instrument for the quantification of the aggregation behavior of charged species. The fluorimetry technique is very sensitive to changes in micropolarity that result from the surfactant aggregation. Data of the two alternative techniques are consistent with those obtained by tensiometry (Table 1).

The size characteristics of the IA-12/PAA binary systems were evaluated using the dynamic light scattering technique for amphiphile concentrations beyond $\mathrm{CAC}_{1}$ (Figure 3). This method allows characterizing the hydrodynamic diameter $\mathrm{D}_{\mathrm{H}}$ of mixed aggregates and proposes their morphology in aqueous solutions. As can be seen, large particles with a $\mathrm{D}_{\mathrm{H}}$ of 100-150 nm are formed, which can increase to $350 \mathrm{~nm}$ with the amphiphile concentration in some cases. Earlier, we reported that the hydrodynamic diameter of individual amphiphile aggregates is $4-6 \mathrm{~nm}$, and they most likely have a spherical shape [43]. Taking into account the small size of the particles in the individual PAA solutions $\left(D_{\mathrm{H}}=\sim 2 \mathrm{~nm}\right)$, it should be suggested that aggregates with a size of $\geq 100 \mathrm{~nm}$ are formed in mixed IA12/PAA systems due to electrostatic attraction forces. Analogous trends in the variation of $D_{\mathrm{H}}$ with the amphiphile concentration are observed for all three fixed PAA concentrations. First, the aggregate sizes increase with the surfactant concentration, whereafter a decrease in the sizes occurs (Figure 3). The largest size of complexes probably reflects the agglomeration of IA-12 and PAA macromolecules close to the isoelectric point. The comparison of the number-averaged size distributions with intensity-averaged data reveals that good agreement occurred in the majority of systems (Figure 3). However, bimodal intensity-averaged size distributions could be seen in some cases, indicating an increase in the polydispersity of the system.

Additional information can be obtained through the analysis of correlation functions (Figures S3-S5). Aggregates of a smaller size show faster diffusion; hence, decay of the correlation function to the baseline occurs for a shorter period of time. In the case of the larger aggregates, the time of decay increased. For the IA-12/PAA $1 \mathrm{mM}$ binary system (Figure S3), the maximum time of the decay of the correlation function (about $2000 \mu \mathrm{s}$ ) was found at 0.5 and $2 \mathrm{mM}$ amphiphile concentrations. This corresponds to the largest aggregates in this system (Figure 3a). Moreover, the shape of the correlation function provides evidence of the existence of only one type of aggregate in the polymercolloid solutions. This trend is observed for all the IA-12/PAA binary systems studied (Figures S3-S5). 

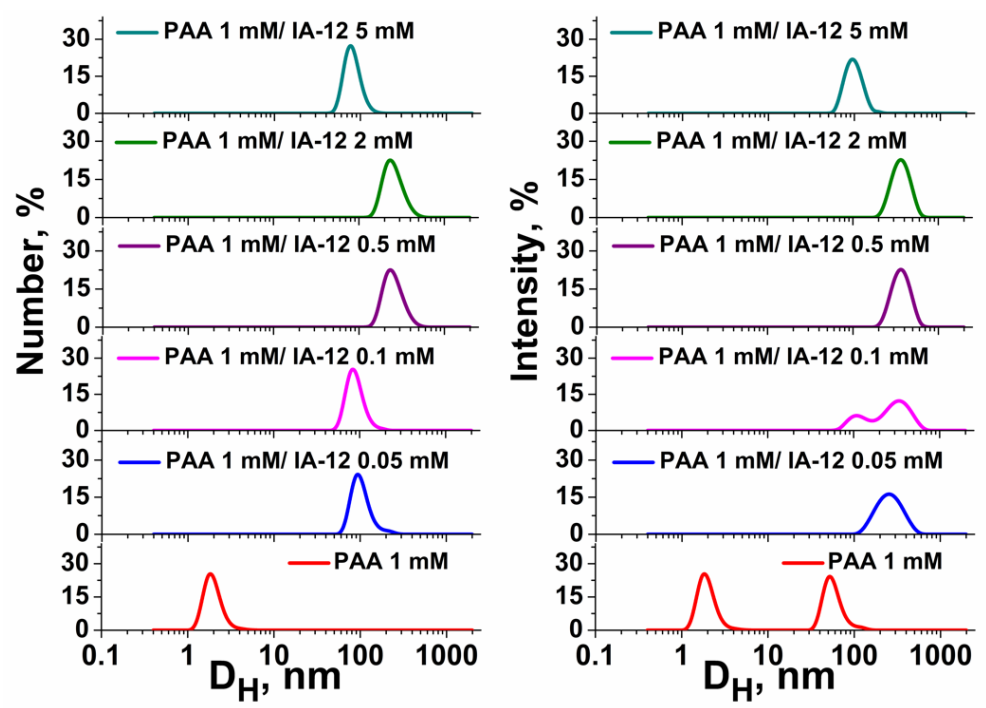

(a)
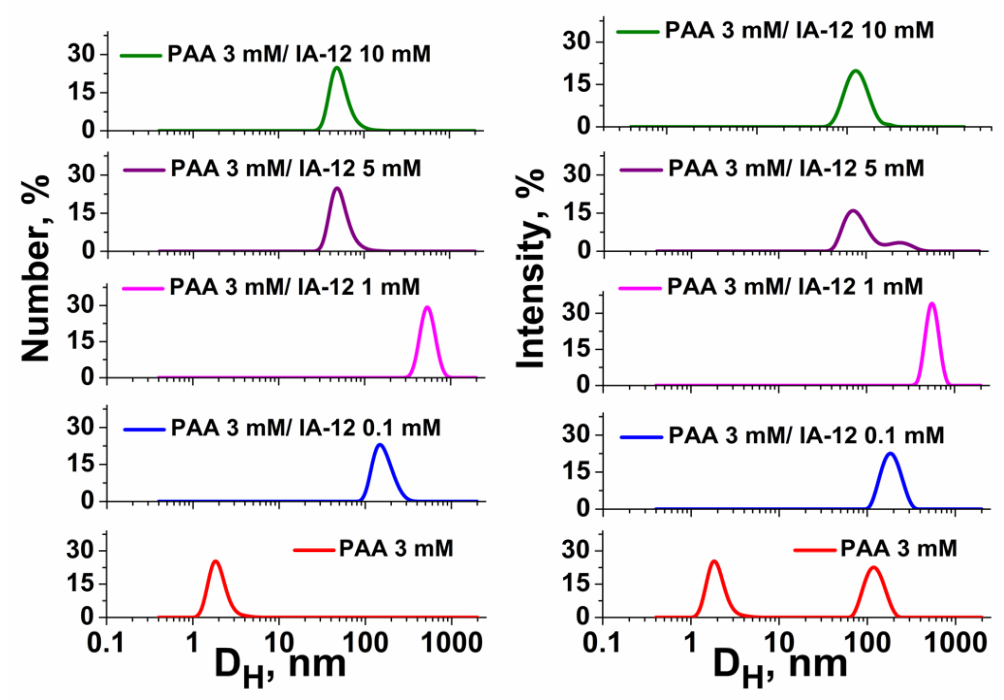

(b)
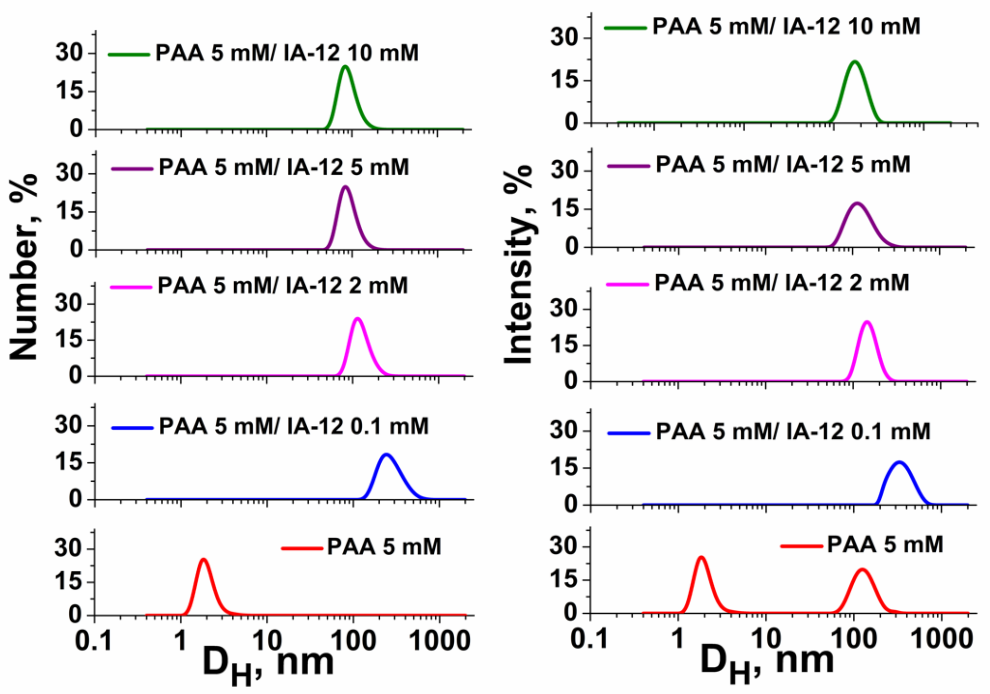

(c)

Figure 3. Number- and intensity-averaged size distribution for the IA-12/PAA binary systems at various fixed PAA concentrations: (a) $1 \mathrm{mM}$; (b) $3 \mathrm{mM}$; (c) $5 \mathrm{mM} ; 25^{\circ} \mathrm{C}$. 
The charge characteristics of the binary IA-12/PAA systems were evaluated using the electrophoretic light scattering technique. The data shown in Figure 4 and Figure S6 testify that an increase in the surfactant concentration is accompanied by a compensation of the negative charge of the PAA anion up to a zero value, after which positively charged systems appeared. Unlike the data available [42], the isoelectric point corresponding to the zero zeta potential of binary systems is practically unaffected by the PAA concentration. This can be due to several factors. First, PAA is a weak polyelectrolyte, and its charge behavior is strongly determined by the solution $\mathrm{pH}$. Under spontaneous conditions, the solution $\mathrm{pH}$ is close to four (Figure S7). A slight decrease is observed with an increase in the surfactant concentration. The latter is probably caused by the shift of the $\mathrm{pK}_{\mathrm{a}}$ value induced by micelles. Under these conditions, only $8 \%$ of carboxylic groups are ionized [41], which is probably responsible for the weak influence of the polyelectrolyte concentration on electrostatic interactions. Second, the charge behavior of the IA-12/PAA binary systems can be guided by a fine balance between several factors, including the variation in the solution $\mathrm{pH}$ as a function of the polymer and surfactant concentration and a shift in $\mathrm{pK}_{\mathrm{a}}$ values. Therefore, no simple correlation is observed in this case. Third, additional information can be obtained from the turbidity data, demonstrating that binary systems tend to become inhomogenous close to an equimolar ratio (Figure 5); therefore, some discrepancy of data in this concentration range can occur.

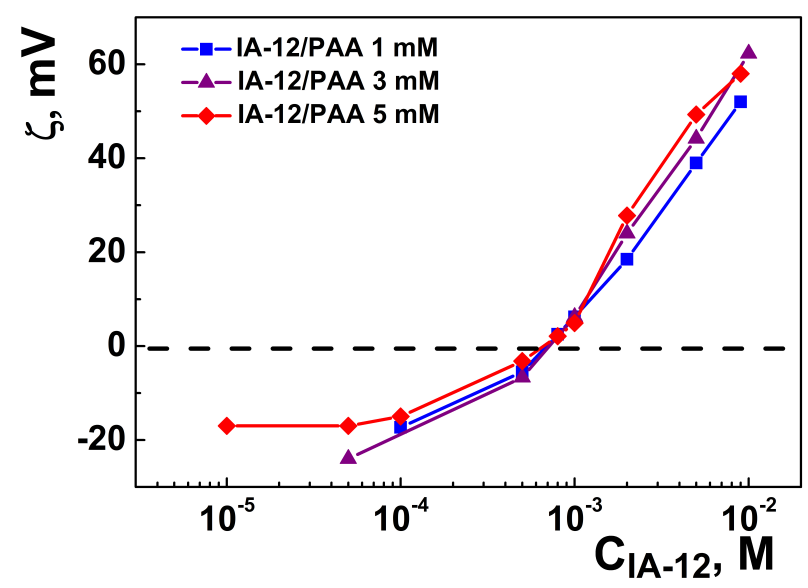

Figure 4. Zeta potential versus IA-12 concentration plot for the IA-12/PAA binary systems; $25^{\circ} \mathrm{C}$.

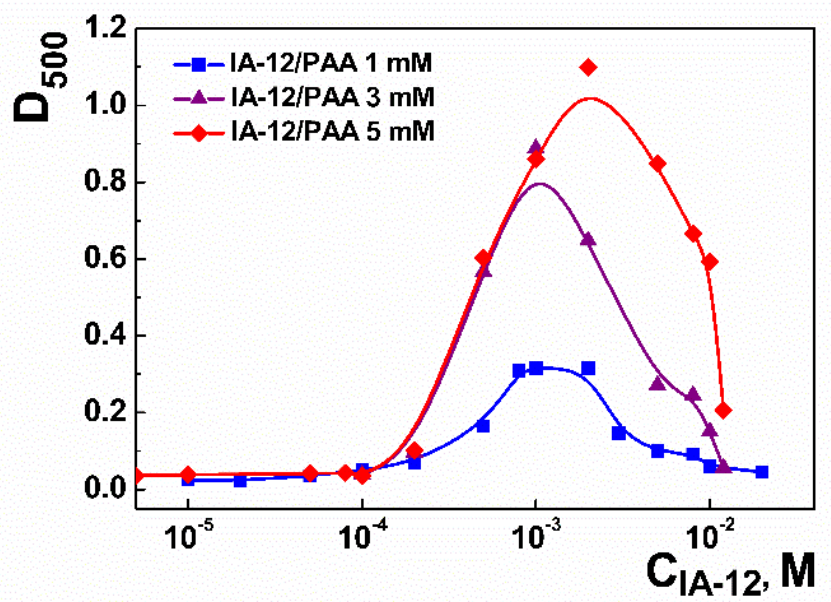

Figure 5. Optical density at $\lambda=500 \mathrm{~nm}$ versus IA- 12 concentration plot for the IA-12/PAA binary systems; $\mathrm{C}_{\mathrm{PAA}}=1,3,5 \mathrm{mM}, 25^{\circ} \mathrm{C}$. 
In all cases, an increase in the IA-12 concentration results in the enhancement of the opalescence in the system followed by its disappearance, with a further increase in the micelle concentration (Figure 5). It is noteworthy that the turbidimetric data are in good accordance with the above variation in zeta potential in the systems. The highest absorbance was detected in the area of the isoelectric points of the systems, while the solutions were more transparent in the region of the existence of positive or negative zeta potential. This phenomenon could be caused by the fact that uncharged colloid species tend to aggregate, thereby inducing inhomogeneity. On the contrary, charged particles are more stable due to electrostatic repulsion preventing their aggregation and sedimentation. As can be seen, the maximum of absorbance shifts to the right with an increase in the PAA concentration, thereby indicating that the charge behavior of the binary systems is influenced by the polyelectrolyte concentration, although this is unobvious from the zeta potential data in Figure 4.

\subsection{Amphiphile/DNA Decamer Interactions}

The next step of the study was dedicated to the interactions between the imidazoliumcontaining amphiphile and DNA decamer (oligonucleotide (oNu)). These investigations allow simulating the binding of IA-12 with nucleotide units of DNA. Initially, the size and charge characteristics of IA-12/DNA decamer complexes were evaluated, and the binding parameters of the components were quantified. To this end, methods of dynamic and electrophoretic light scattering and fluorescence spectroscopy were used. Dynamic light scattering was applied for the determination of the hydrodynamic diameter of particles in the IA-12/oNu binary system (Figure 6). As can be seen, binding of the components responsible for the complex formation is observed. This is evident from the enlargement of the $\mathrm{D}_{\mathrm{H}}$ value of particles from $2 \mathrm{~nm}$ for an individual oNu to $50 \mathrm{~nm}$ and higher sizes (up to $250 \mathrm{~nm}$ ) for the IA-12/oNu binary systems. It is noteworthy that these sizes are optimal for biotechnological purposes because they allow the nanoparticles to circulate in the bloodstream for a long time [44].

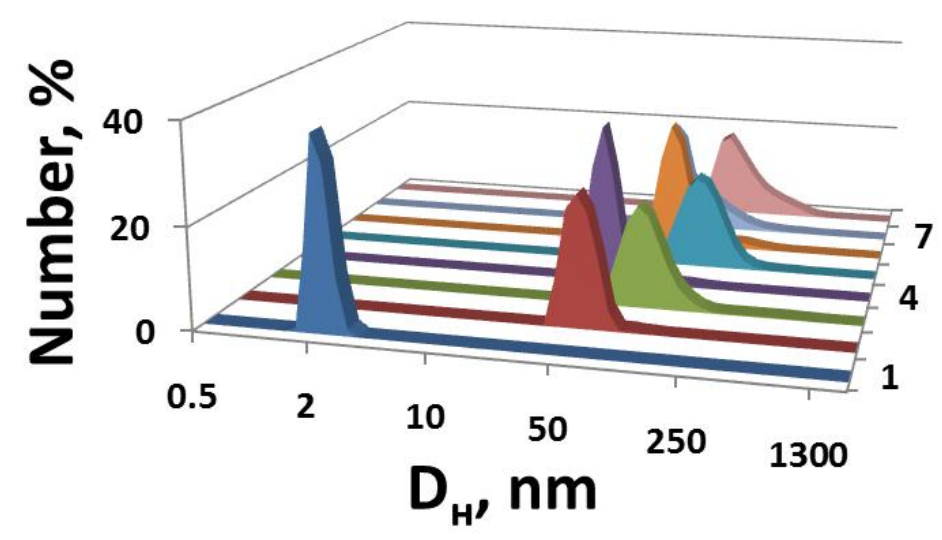

Figure 6. Number-averaged size distribution for the IA-12/oNu binary system at various amphiphile/oNu molar ratios: 1 -individual oNu, 2-0.02, 3-0.045, 4-0.094, 5-0.194, 6-0.394, 7-0.79, 8-1.2; $9-3.9 ; 25^{\circ} \mathrm{C}$.

Another important criterion for the efficacy of potential nonviral vectors is their ability to neutralize the negative charges of nucleotide units, which was examined by the electrophoretic light scattering method (Figure 7). It was demonstrated that IA-12 has a weak ability of oNu charge compensation ( $\Delta \xi$ does not exceed $20 \mathrm{mV}$ ); the isoelectric point was not achieved even with the excess of amphiphile. This trend has earlier been reported for the higher homologs of IA-12 [45], which was attributed to the fact that the delocalized positive charge of the imidazolium group cannot compensate for the negative charge of the phosphate backbones. 


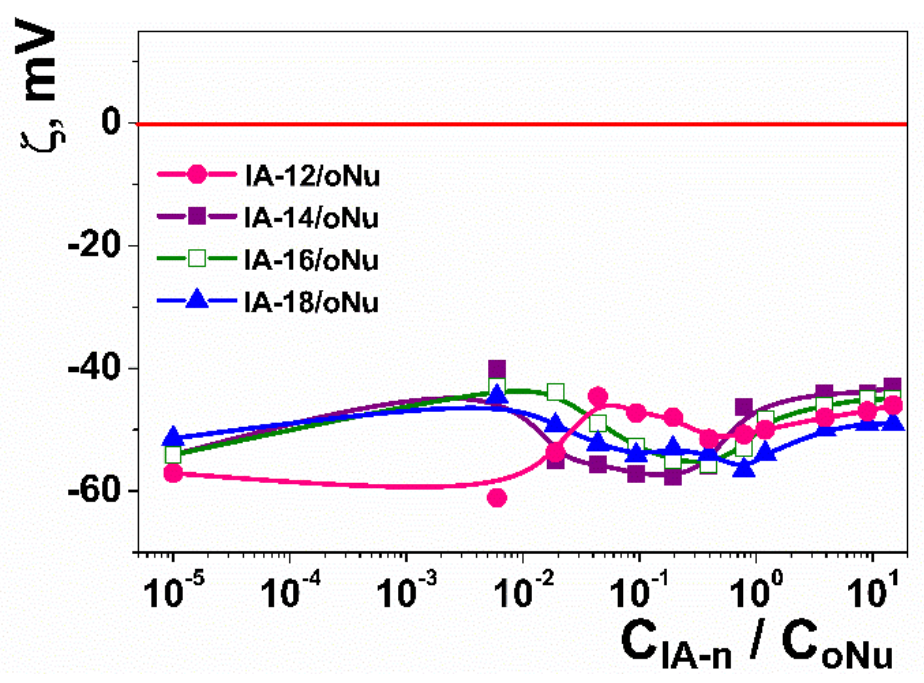

Figure 7. Electrokinetic potential versus amphiphile/oNu molar ratio for the IA-12/oNu, IA14/oNu [45], IA-16/oNu [45] and IA-18/oNu [45] binary systems; $25^{\circ} \mathrm{C}$.

To test whether a DNA oligomer can be used for the reliable prediction of the binding behavior of macromolecular analogs, electrophoretic analysis involving pDNA was carried out (Figure 8), which demonstrated that IA-12 does not bind with pDNA in a wide concentration range of the amphiphile. Some retardation of both supercoiled and relaxed forms of pDNA was, however, observed at increased N/P ratios from 38:1 to 300:1, indicating a weak interaction of the cationic surfactant with pDNA. The typical cationic surfactant $\mathrm{CTAB}$ used as a reference compound was shown to completely bind pDNA at an N/P ratio of 14:1 (Figure S9). The DNA-binding ability of CTAB was inferior to that observed for cationic polymers such as cationic polyaspartamides with an N/P ratio as low as 1:1 [46]. These data are in good agreement with the above zeta potential results of the IA- $12 / \mathrm{oNu}$ complexes, testifying that electrostatic interactions play a minor role in the complexation. Unlike ammonium surfactants, imidazolium head groups with delocalized cationic charge give an insufficient contribution to phosphate anion neutralization.

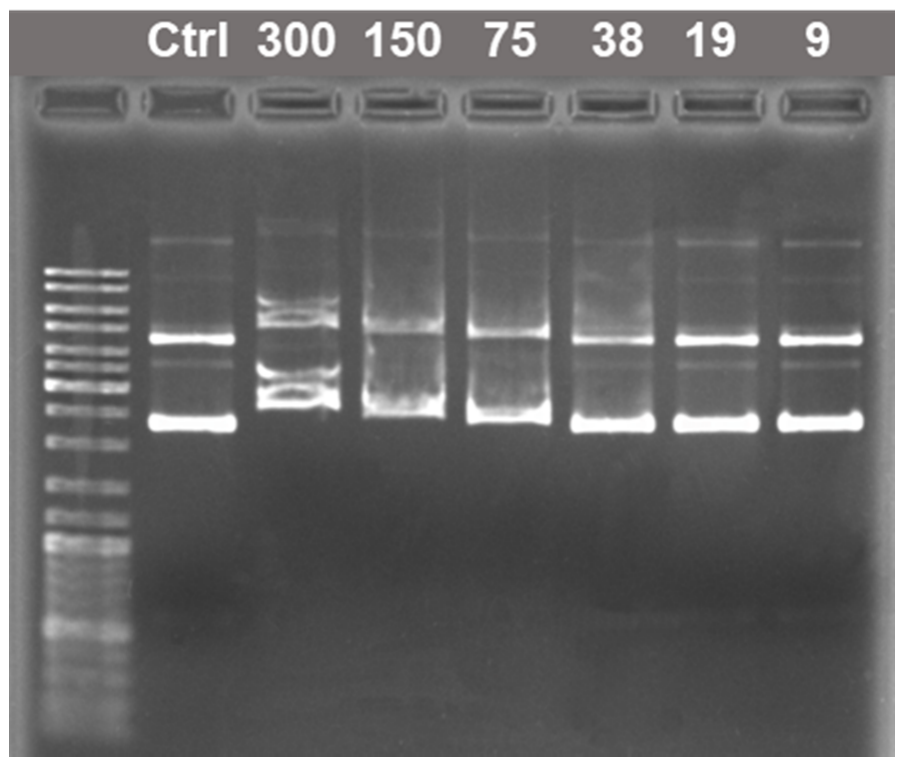

Figure 8. Electrophoretic mobility of pDNA in a complex with IA-12. Ctrl shows pure pDNA. N/P ratios are indicated above the corresponding wells. A DNA ladder from 100 to 10,000 bp was used. 
DNA-surfactant complexes were characterized by the DLS technique at an N/P ratio of 10:1 (Figures S10-S12). CTAB formed with pDNA well-defined nanosized complexes $\left(\mathrm{D}_{\mathrm{H}}\right.$ $267 \mathrm{~nm}$, PDI 0.234 ) with a highly positive zeta potential, indicating the condensation and cationization of pDNA by the surfactant. Under the same conditions, IA-12 neither packed pDNA nor induced its cationization, further showing the lack of its strong electrostatic interaction with pDNA and, therefore, the different DNA-binding properties of IA-12 compared to CTAB.

The additional quantification of IA-12/oNu binding was carried out using the fluorescence technique and ethidium bromide (EB) as an intercalation probe. This approach is based on the exclusion of EB from the complexes by surfactant molecules, which is accompanied by the quenching of EB fluorescence. Emission spectra of $\mathrm{EB} / \mathrm{oNu}$ complexes at various IA-12 concentrations (Figure S13) demonstrate that the higher the amphiphile concentration, the lower the intensity of the corresponding band. Fluorescence spectra for various IA-12/oNu molar ratios were used for the calculation of the IA-12/oNu binding degree $\beta$ (Figure 9) using Equation (1). An increase in the amphiphile concentration is shown to induce an increase in the $\beta$ value up to $75 \%$ under IA- 12 excess, while no charge neutralization was observed in this range (Figure 7). It is noteworthy that earlier reported data for higher homologs of IA-12 (tetradecyl, hexadecyl and octadecyl derivatives) exhibited an almost quantitative binding of oNu [45]. This emphasizes the crucial role of the hydrophobic effect and cooperative interactions in the binding efficacy of imidazolium surfactants toward nucleotides. It can be proposed that an alternative intercalation mechanism of binding probably occurs apart from a weak electrostatic contribution. This is based on the fact that amphiphiles with a planar aromatic imidazolium head group are capable of locating nucleobases. Importantly, the alkyl tail length of imidazolium amphiphiles strongly determines their intercalation ability. In particular, homologs with shorter alkyl tails cannot interact with polynucleotides in such a way [47]. Comparative analysis of data obtained for imidazolium homological series allows us to conclude that the superposition of two factors controls the IA-12 complexation with a DNA decamer, namely hydrophobic binding and the intercalation mechanism.

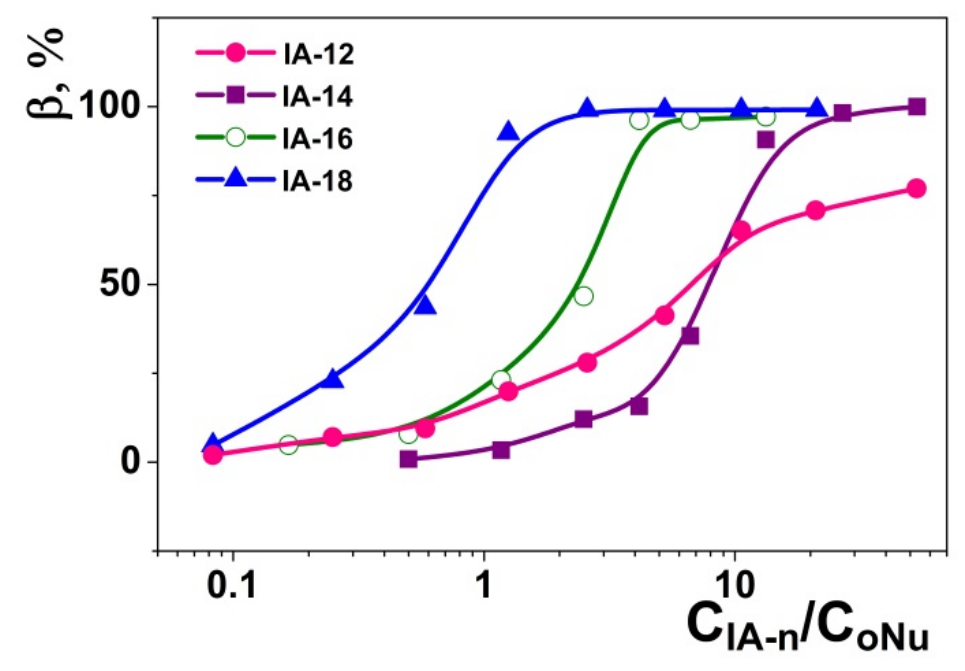

Figure 9. Binding degree of IA- 12 with oNu versus IA-n concentration plot for the IA- $12 / \mathrm{oNu}$, IA-14/oNu [45], IA-16/oNu [45] and IA-18/oNu [45] mixtures; $25^{\circ} \mathrm{C}$.

To test whether the IA-12/oNu complex could be transfected through the cell barrier to its interior, a fluorescence microscopy technique was used. Figure 10 demonstrates HeLa cancer cells stained with Hoechst 33342 in the absence and in the presence of the IA-12/oNu complexes. This dye is capable of binding with both DNA of the nucleus of HeLa cells (Figure 10a), and the added oNu marked them with blue. In Figure 10b, the blue nimbus corresponding to oNu localization is clearly seen close to the stained nucleus 
of the HeLa cell, which indicates that successful penetration of the complexes through the cell barrier occurred.

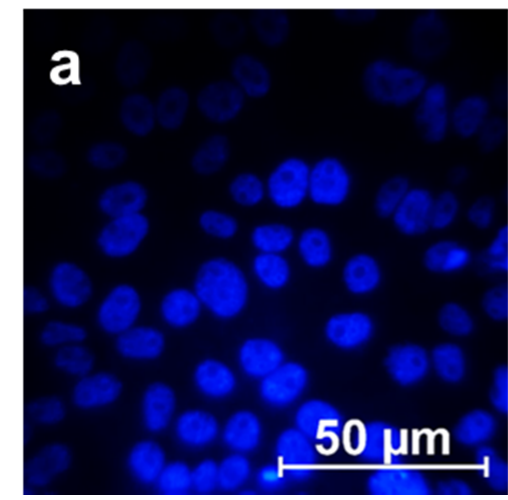

(a)

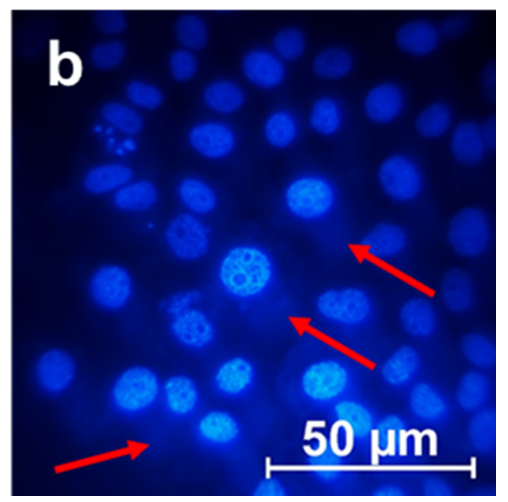

(b)

Figure 10. Fluorescent micrographs of HeLa cells in the absence (a) and in the presence of the IA-12/oNu complex $(\mathbf{b}) ; \mathrm{C}_{\mathrm{oNu}}=1 \mathrm{mM}, \mathrm{C}_{\mathrm{IA}-12}=0.5 \mathrm{mM}$. The arrow indicates the presence of oligonucleotide in the cytoplasm of cells.

The cellular uptake of the IA-12/oNu complexes was further testified using flow cytometry (Figure 11). Untreated cells were used as negative controls. After treatment with substances, M-HeLa cells were fixed and stained with Hoechst 33342 (blue), which was used as a fluorescent probe. The dye allows one to mark cell nuclei and oNu penetrated into cells in the form of blue spots. It was shown that upon treatment with IA- $12 / \mathrm{oNu}$ complexes, the fluorescence intensity was higher than in the control, which indicates that the penetration of the test complexes into M-HeLa cells occurred.
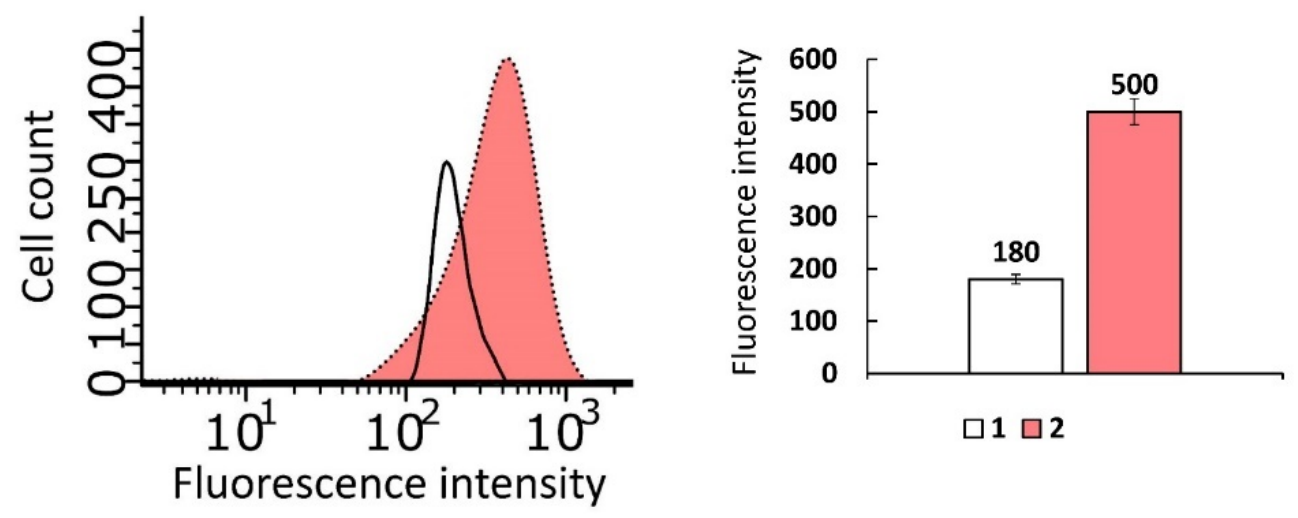

Figure 11. Cellular uptake study of the IA-12/oNu complex. 1-Intact M-HeLa cells; 2-M-HeLa cells in the presence of the IA- $12 / \mathrm{oNu}$ complex.

From the viewpoint of a practical application, cytotoxicity is an essential characteristic of the systems. Table 2 summarizes the cytotoxic effect of the single IA-12 solution and IA-12/oNu complexes toward M-HeLa and Chang liver cell lines. Cationic surfactants are typically characterized by a rather high cytotoxicity, which is confirmed by the $\mathrm{IC}_{50}$ values of IA-12 given in Table 2, with a higher cytotoxic effect occurring against Chang liver cells. However, the transition to the binary IA-12/oNu complex is accompanied by the appearance of selectivity in cytotoxic action, namely a sharp decrease in $\mathrm{IC}_{50}$ values (to $1.1 \mu \mathrm{M}$ ), which occurs with cancer cells along with an increase in the viability of normal cells. Analogous changes in cytotoxic activity are documented in [48], where an MTT test revealed a decrease in the cytotoxicity of complexes compared to single cationic surfactants. 
Table 2. The cytotoxic effect of IA-12 in the individual system and in the binary system with oNu toward normal and tumor human cell lines.

\begin{tabular}{cccc}
\hline \multicolumn{5}{c}{ IC $_{50} \boldsymbol{\mu M}$} \\
\hline M-HeLa & & \multicolumn{2}{c}{ Chang Liver } \\
\hline IA-12 & IA-12/oNu & IA-12 & IA-12/oNu \\
\hline $39 \pm 0.1$ & $1.1 \pm 0.08$ & $17.0 \pm 0.1$ & $21.3 \pm 1.8$ \\
\hline
\end{tabular}

\subsection{Membranotropic Properties and Cell Penetration}

Another important feature of drug and gene delivery systems based on amphiphilic compounds is their ability to pass through cell membranes composed of lipid bilayers. With this in mind, the ability of IA-12 to integrate with dipalmitoylphosphatidylcholine (DPPC) liposomes was examined. This property was studied using the turbidimetric titration of DPPC liposome dispersion by IA-12 solution to determine the temperature of the gel/liquid crystal phase transition. In the absence of foreign compounds, the temperature of the DPPC main phase transition ( $\mathrm{T}_{\mathrm{PT}}$ ) equals $41 \pm 0.1^{\circ} \mathrm{C}$ (Figure S14). Therein, $\mathrm{T}_{\mathrm{PT}}$ is taken as the inflection point in reversed S-shape plots. Surfactants and other additives are capable of changing the $\mathrm{T}_{\mathrm{PT}}$ value due to ordering or disturbing the lipid bilayer (Figure S14). Figure 12 visualizes turbidimetric data in terms of the temperature of the main phase transition versus the IA-12/DPPC molar ratio. The initial decrease in the $\mathrm{T}_{\mathrm{PT}}$ value with the IA- 12 concentration indicates the integration of amphiphile molecules in the lipid bilayer that resulted in the disordering of DPPC alkyl chains. This promotes an increase in the permeability of the lipid bilayer that could be used for biotechnological tasks. The slope of dependence became higher at $\mathrm{C}_{\mathrm{IA}-12} / \mathrm{C}_{\mathrm{DPPC}} \geq 0.1$, which can be attributed to the solubilization of liposomes in IA-12 aggregates.

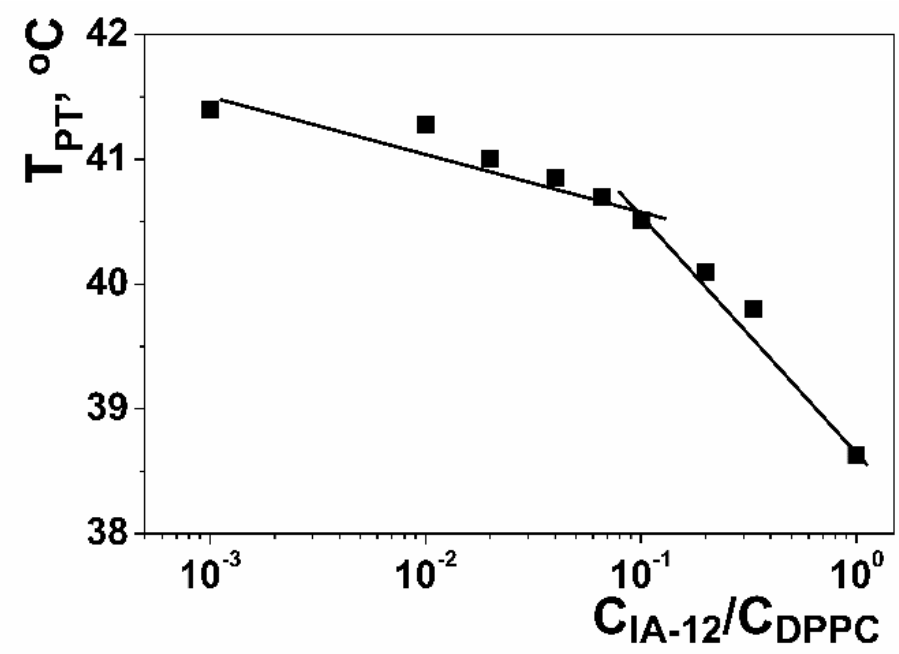

Figure 12. DPPC main phase transition temperature versus the amphiphile/lipid molar ratio plot for the IA-12/DPPC binary system.

\section{Materials and Methods}

\subsection{Chemicals}

Imidazolium amphiphile IA-12 was synthesized in accordance with the standard experimental procedure $[45,49]$. Commercially available double-stranded oligonucleotide $(\mathrm{oNu})$ with 10 nucleotide units in each strand (GCGTTAACGC, molecular weight is $3028 \mathrm{~g} / \mathrm{mol}$, Joint Stock Company Syntol, Moscow, Russia) was used. Plasmid DNA (pDNA) pVax1-DsRed (3665 bp) was kindly gifted by Dilara Gatina (Omics Technology Laboratory, Kazan Federal University, Kazan, Russia). Agarose for molecular biology, ethidium bromide and hexadecyltrimethylammonium bromide $(\geq 99.0 \%)$ were purchased 
from Sigma-Aldrich. As probes for fluorometric measurements, ethidium bromide (SigmaAldrich, St. Louis, MO, USA, 95\%) and pyrene (Sigma-Aldrich, St. Louis, MO, USA, 99\%) were used. Lipoid PC 16:0/16:0 (1,2-dipalmitoyl-sn-glycero-3-phosphocholine, DPPC) was a gift from Lipoid GmbH (Ludwigshafen, Germany). Hoechst 33342 (Sigma-Aldrich, St. Louis, MO, USA, 99\%) was applied for the fluorescence microscopy assay. Polyacrylic acid with an average molecular weight of $1800 \mathrm{~g} / \mathrm{mol}$ (Sigma-Aldrich, St. Louis, MO, USA, $99 \%$ ) was used. Polymer concentrations were given as a molar concentration on a monomer basis. Purified water $\left(18.2 \mathrm{M} \Omega \mathrm{cm}\right.$ resistivity at $\left.25^{\circ} \mathrm{C}\right)$ from Direct-Q $5 \mathrm{UV}$ equipment (Millipore S.A.S. 67120 Molsheim-France) was used for all solution preparation.

\subsection{Preparation of Samples}

Liposome preparation was carried out by the thin lipid hydration technique as follows [49-51]: a specific amount of DPPC (5.4 mg) was solved in $100 \mu \mathrm{L}$ of chloroform. The solvent was removed by evaporation overnight at room temperature. The obtained lipid film was suspended by $1 \mathrm{~mL}$ of water and thermostated at $55-60{ }^{\circ} \mathrm{C}$ in a water bath for $30 \mathrm{~min}$. The fabricated rude suspension was frozen and thawed 5 times using liquid nitrogen and a water bath $\left(60^{\circ} \mathrm{C}\right)$, respectively. After that, the dispersion was extruded 21 times by using a syringe extruder (LiposoFast Basic, Avestin, Ottawa, ON, Canada) through a polycarbonate filter with $100 \mathrm{~nm}$ pores.

A stock solution of a DNA decamer was prepared by the dissolvation of commercial crystalline oligonucleotide in $4 \mathrm{mM}$ Tris- $\mathrm{HCl}$ buffer $(\mathrm{pH}=8.0)$ and its dilution down to $10 \mathrm{mM}$ (concentration per nucleotide unit). The mixture was heated at $95^{\circ} \mathrm{C}$ for $5 \mathrm{~min}$ and immediately chilled in an ice bath.

\subsection{Methods}

\subsubsection{Tensiometry}

A Krûss K06 tensiometer (Hamburg, Germany, Du Nouy ring detachment method) was used for measurements of the surface tension of the amphiphile/PAA binary systems. The volume of amphiphiles solutions was $10 \mathrm{~mL}$. The sample was thermostated for $5 \mathrm{~min}$ at $25^{\circ} \mathrm{C}$ before measurement. Detachment of the ring for each sample was repeated at least 3 times, and measurements with a deviation of $\leq 0.1 \mathrm{mN} / \mathrm{m}$ were taken into account.

\subsubsection{Conductometry}

Specific conductivity was measured using an Inolab Cond 720 conductometer at $25^{\circ} \mathrm{C}$. The sample was thermostated for $5 \mathrm{~min}$ at $25^{\circ} \mathrm{C}$ before measurement. Specific conductivity values with a deviation of no more than $\pm 1 \mu \mathrm{Sm} / \mathrm{cm}$ were taken into account.

\subsubsection{Fluorescence Spectroscopy}

A survey of the emission fluorescence spectra of pyrene was performed using a Cary Eclipse G9800A fluorescence spectrophotometer (Agilent Technologies, Santa Clara, CA, USA) at $25^{\circ} \mathrm{C}$. The excitation wavelength was $335 \mathrm{~nm}$. Emission spectra were registered in the range of $350-500 \mathrm{~nm}$ with a constant scanning speed $(120 \mathrm{~nm} / \mathrm{min})$. A cuvette with a $1 \mathrm{~cm}$ width was used in all measurements. Fluorescence intensities of the first $\left(I_{\mathrm{I}}\right)$ and third ( $\left.I_{\text {III }}\right)$ vibrational peaks of pyrene at $373 \mathrm{~nm}$ and $384 \mathrm{~nm}$, respectively, were extracted from the collected spectra.

Fluorescence spectra of the oligonucleotide-ethidium bromide complexes were recorded in the range from 500 to $700 \mathrm{~nm}$ at an excitation wavelength of $480 \mathrm{~nm}$. A $0.8 \mathrm{~mL}$ sample containing $0.5 \mu \mathrm{M}$ of EB and a $10 \mu \mathrm{M}$ concentration of oligonucleotide (counting on 1 nucleotide unit) in $4 \mathrm{mM}$ Tris- $\mathrm{HCl}$ buffer $(\mathrm{pH}=8.0)$ was equilibrated for $10 \mathrm{~min}$ at $25^{\circ} \mathrm{C}$. After that, a specific aliquot of the amphiphile solution was added to the mixture, and the fluorescence emission spectrum was registered $[52,53]$. Each concentration dependence was performed 2 times, and the standard deviation of the results was less than $2 \%$. The 
following equation was used for the quantitative evaluation of the binding degree of oNu to amphiphile:

$$
\beta=\left(I_{\text {bound }}-I_{\text {obs }}\right) /\left(I_{\text {bound }}-I_{\text {free }}\right)
$$

where $I_{\text {free }}$ and $I_{\text {bound }}$ are the intensities of fluorescence of free EB and probe bound to oNu, respectively; and $I_{\mathrm{obs}}$ is the fluorescence intensity observed during titration measurements at a specific amount of amphiphile added.

\subsubsection{Dynamic and Electrophoretic Light Scattering}

Measurements of size and charge characteristics of samples were carried out using dynamic and electrophoretic light scattering techniques at Malvern ZetaSizer Nano ZS apparatus (Malvern Instruments Ltd., Malvern, UK). A source of irradiation was a He-Ne gas laser with $4 \mathrm{MW}$ power $\left(\lambda_{\text {operating }}=633 \mathrm{~nm}\right)$. Collected signals were treated in terms of frequency and phase analysis of scattered light using software attached to the device. All measurements were carried out at a $173^{\circ}$ scattering angle. Computation of particle size was performed in accordance with the Stokes-Einstein equation [54]:

$$
\mathrm{D}=\mathrm{kT} /(6 \pi \eta \mathrm{R})
$$

where $\mathrm{k}$ is the Boltzmann's constant, $\mathrm{T}$ is the absolute temperature, $\eta$ is the solvent's viscosity and $\mathrm{R}$ is the hydrodynamic radius.

The zeta potential calculation was based on three measurements of electrophoretic mobilities using the Smoluchowski relationship:

$$
\zeta=\mu \eta / \varepsilon
$$

where $\zeta$ is the zeta potential, $\eta$ is the dynamic viscosity of the solution, $\mu$ is the mobility of the particle and $\varepsilon$ is the dielectric constant [55].

The hydrodynamic diameter and zeta potential of pDNA complexes with IA-12 and CTAB were measured on a ZetaSizer Nano ZS analyzer (Malvern Instruments) in a Ucuvette in $50 \mathrm{mM}$ HEPES buffer $(\mathrm{pH}=7)$. The final concentration of DNA and the N/P ratio were $10 \mu \mathrm{g} / \mathrm{mL}$ and 10:1, respectively, for both complexes.

\subsubsection{Electrophoretic Analysis}

To obtain complexes, pDNA at a final concentration of $10 \mu \mathrm{g} / \mathrm{mL}$ was gently mixed with IA-12 (90-3000 $\mu \mathrm{g} / \mathrm{mL})$ or CTAB (5-160 $\mu \mathrm{g} / \mathrm{mL})$ in phosphate-buffered saline (PBS). The mixture was incubated at ambient temperature for $20 \mathrm{~min}$. Electrophoretic analysis of pDNA-surfactant complexes was performed in 1\% agarose gel in Tris-acetate-EDTA buffer using electrophoresis apparatus (Bio-Rad Laboratories, Hercules, CA, USA). Electrophoresis conditions were detailed previously [46]. Briefly, pDNA (200 ng per well) was separated at a voltage of $8 \mathrm{~V} / \mathrm{cm}$ for $60 \mathrm{~min}$ and then stained with ethidium bromide $(0.5 \mu \mathrm{g} / \mathrm{mL})$. The gels were visualized using a ChemiDoc ${ }^{\mathrm{TM}}$ XRS Plus gel documentation system (BioRad Laboratories, Hercules, CA, USA). O'Gene Ruler DNA Ladder Mix (100-10,000 bp) (Fermentas, Waltham, MA, USA) was used.

\subsubsection{Turbidimetry}

The phase behavior of amphiphile/PAA binary mixtures was studied using a Specord 250 PLUS spectrophotometer (Analytik Jena, Jena, Germany). An aliquot of polyelectrolyte solution was added to IA-12 solution of a specific concentration. The mixture was kept for $2 \mathrm{~min}$, and the optical density of the solution was measured at a $500 \mathrm{~nm}$ wavelength.

Phase transitions in amphiphile/DPPC mixtures were studied using a Specord 250 PLUS spectrophotometer (Analytik Jena, Jena, Germany). An optical density at a $350 \mathrm{~nm}$ wavelength as a function of the temperature was registered for the establishment of the lipid main phase transition in the IA-12/DPPC binary system. The temperature varied in the range from 35 to $45^{\circ} \mathrm{C}$. Primarily, a turbidimetric plot for individual DPPC liposomes $(0.7 \mathrm{mM})$ was obtained. Further, an aliquot of $5 \mathrm{mM}$ amphiphile solution was added to the 
liposome dispersion, and an analogous turbidimetric plot was registered. These operations were repeated for several added aliquots of amphiphile solution. Turbidimetric plots were fitted in accordance with the van 't Hoff two-state model, which assumes that the inflection point in the turbidimetric plot corresponds to the main phase transition of DPPC.

\subsubsection{Fluorescence Microscopy}

Hoechst 33342 dye $(0.1 \mathrm{mg} / \mathrm{mL})$ was used as a contrast agent to localize the oligonucleotide. This dye binds to double-stranded DNA with a preference for domains enriched in adenine and thymine. Experiments were carried out using a Nikon Eclipse Ci-S fluorescence microscope (Nikon, Tokyo, Japan) at a magnification of $1000 \times$ and by means of the multifunctional Cytell Cell Imaging system (GE Health Care Life Science, Umeå, Sweden) using Automated Imaging BioApp at a magnification of $1000 \times$.

\subsubsection{Flow Cytometry Assay}

M-HeLa cells at $1 \times 10^{6}$ cells/well were seeded in six-well plates. After $24 \mathrm{~h}$ of incubation, the IA-12/oNu complex was added to the test wells at a concentration of $0.5 \mu \mathrm{M}$. The uptake of the IA-12/oNu complex cells was analyzed using flow cytometry (Guava easyCyte 8HT, Luminex Corporation, Austin, TX, USA). Untreated cells were used as negative controls.

\subsubsection{In Vitro Cytotoxicity Assay}

The evaluation of the toxicity of the IA-12 and IA-12/oNu systems was estimated by means of the multifunctional Cytell Cell Imaging system (GE Health Care Life Science, Sweden) using the Cell Viability Bio App. Cell lines M-HeLa (epithelial carcinoma of the cervix, HeLa subline, M-HeLa clone) were acquired from the Type Culture Collection of the Institute of Cytology (Russian Academy of Sciences, Saint Petersburg, Russia) and Chang liver normal cells from the N.F. Gamaleya Research Center of Epidemiology and Microbiology (Moscow, Russia). The cells were seeded in a concentration of $10^{5}$ cells $/ \mathrm{mL}$ in 96-well plates (Eppendorf, Hamburg, Germany), then $150 \mu \mathrm{L}$ of standard Eagle's medium (PanEco, Moscow, Russia) was added per well, and incubation proceeded with $\mathrm{CO}_{2}$ at $37{ }^{\circ} \mathrm{C}$. The medium was then supplemented with $10 \%$ fetal calf serum and $1 \%$ nonessential amino acids. Twenty-four hours after seeding, the systems under study were added at preset dilutions, $150 \mu \mathrm{L}$ to each well. The dilutions were prepared immediately in a nutrient medium. The experiments were repeated three times. Intact cells cultured in parallel with experimental cells were used as a control.

\section{Conclusions}

In this study, complexation in mixed systems based on imidazolium amphiphile IA-12 and poly- or oligomeric anions of synthetic and natural origin was demonstrated. The addition of polyacrylic acid to a single surfactant system markedly reduces the aggregation thresholds of the system by ca. 200 times and leads to the electrostatically driven formation of stable polymer-colloid complexes with a hydrodynamic diameter of 100-150 nm. Unlike synthetic polyelectrolytes, the complexation of IA-12 with oligonucleotide is not electrostatically mediated, as evidenced by weak charge neutralization demonstrated by the zeta potential study and gel electrophoresis experiments. At the same time, high IA$12 / \mathrm{oNu}$ complexation efficacy is testified by ethidium bromide quenching data. Turbidity measurements demonstrated the membrane tropic ability of the imidazolium surfactant, after which the cellular uptake of the IA-12/oNu complex was proved by fluorescence microscopy and flow cytometry data. Selective cytotoxicity of the complexes was observed toward M-HeLa cells with $\mathrm{IC}_{50}=1.1 \mu \mathrm{M}$, while a markedly higher value of $\mathrm{IC}_{50}=23.1 \mu \mathrm{M}$ was determined for Chang liver cells.

Supplementary Materials: The following are available online. Figure S1: Specific conductivity versus amphiphile concentration plot for individual IA-12 solutions and IA-12/PAA binary systems at fixed PAA concentrations; $25^{\circ} \mathrm{C}$. Figure S2: Intensity ratio of the first and third vibronic peaks of 
pyrene vs. amphiphile concentration for the IA-12/PAA binary systems at fixed PAA concentrations; $25^{\circ} \mathrm{C}$. Figure S3: DLS correlation functions for the IA-12/PAA binary system at various amphiphile concentrations and a constant PAA concentration; $\mathrm{C}_{\mathrm{PAA}}=1 \mathrm{mM} ; 25^{\circ} \mathrm{C}$. Figure S4. DLS correlation functions for the IA-12/PAA binary system at various amphiphile concentrations and a constant PAA concentration; $\mathrm{C}_{\mathrm{PAA}}=3 \mathrm{mM} ; 25^{\circ} \mathrm{C}$. Figure S5: DLS correlation functions for the IA-12/PAA binary system at various amphiphile concentrations and a constant PAA concentration; $\mathrm{C}_{\mathrm{PAA}}=5 \mathrm{mM} ; 25^{\circ} \mathrm{C}$. Figure S6: Zeta potential versus IA-12 concentration plot for the IA-12/PAA binary systems; $25^{\circ} \mathrm{C}$ (the linear X-axis). Figure S7: $\mathrm{pH}$ changes in IA-12/PAA aqueous solutions; $25^{\circ} \mathrm{C}$. Figure S8: Molecular weight marker $\mathrm{O}^{\prime}$ Gene Ruler DNA Ladder Mix. Figure S9: Electrophoretic mobility of pDNA in complex with CTAB. Ctrl shows pure pDNA, N/P ratios are indicated above the corresponding wells. A DNA ladder from 100 to 10,000 bp was used. Figure S10: Intensity-averaged size distribution for the IA-12/pDNA system; N/P ratio of $10: 1 ; 25^{\circ} \mathrm{C}$. Figure S11: Intensity-averaged size distribution for $\mathrm{CTAB} / \mathrm{pDNA}$ system; N/P ratio of $10: 1 ; 25^{\circ} \mathrm{C}$. Figure S12: Zeta potential for IA-12/pDNA (green) and $\mathrm{CTAB} / \mathrm{pDNA}$ (red) complexes; N/P ratio of $10: 1 ; 25^{\circ} \mathrm{C}$. Figure $\mathrm{S} 13$. EB/oNu emission fluorescence spectra in the presence of various amounts of IA-12 (the arrow indicates the direction of the increase in the amphiphile concentration); $25^{\circ} \mathrm{C}$. Figure S14: Typical turbidimetric plot for DPPC liposomes in the absence and in the presence of IA-12 (the amphiphile/lipid molar ratio is 1:5), $\mathrm{C}_{\mathrm{DPPC}}=0.7 \mathrm{mM}[56]$.

Author Contributions: Conceptualization, methodology, supervision, L.Y.Z.; experiments, D.A.K., D.M.K., S.S.L., V.M.Z., A.S.S., S.K.A., A.P.L., A.D.V. and D.V.S.; formal analysis, validation, data curation, visualization, writing-original draft preparation, D.A.K.; writing-review and editing, L.Y.Z. and D.R.G. All authors have read and agreed to the published version of the manuscript.

Funding: This research was funded by a government assignment for the FRC Kazan Scientific Center of RAS. D.A.K., D.R.G., D.M.K., S.S.L., A.S.S., S.K.A., A.P.L., A.D.V., L.Y.Z. and D.V.S. acknowledge the Kazan Federal University Strategic Academic Leadership Program.

Institutional Review Board Statement: Not applicable.

Informed Consent Statement: Not applicable.

Data Availability Statement: Data are contained within the article.

Conflicts of Interest: The authors declare no conflict of interest.

Sample Availability: Samples of the compounds are not available from the authors.

\section{References}

1. Varga, I.; Campbell, R.A. General physical description of the behavior of oppositely charged polyelectrolyte/surfactant mixtures at the air/water interface. Langmuir 2017, 33, 5915-5924. [CrossRef] [PubMed]

2. Lele, B.J.; Tilton, R.D. Colloidal depletion and structural force synergism or antagonism in solutions of mutually repelling polyelectrolytes and ionic surfactants. Langmuir 2019, 35, 15937-15947. [CrossRef] [PubMed]

3. Gradzielski, M.; Hoffmann, I. Polyelectrolyte-surfactant complexes (PESCs) composed of oppositely charged components. Curr. Opin. Colloid Interface Sci. 2018, 35, 124-141. [CrossRef]

4. Guzmán, E.; Fernández-Peña, L.; Ortega, F.; Rubio, R.G. Equilibrium and kinetically trapped aggregates in polyelectrolyteoppositely charged surfactant mixtures. Curr. Opin. Colloid Interface Sci. 2020, 48, 91-108. [CrossRef]

5. Guzmán, E.; Llamas, S.; Maestro, A.; Fernández-Peña, L.; Akanno, A.; Miller, R.; Ortega, F.; Rubi, R.G. Polymer-surfactant systems in bulk and at fluid interfaces. Adv. Colloid Interface Sci. 2016, 233, 38-64. [CrossRef]

6. Klučáková, M.; Jarábková, S.; Velcer, T.; Kalina, M.; Pekař, M. Transport of a model diffusion probe in polyelectrolyte-surfactant hydrogels. Colloids Surf. A 2019, 573, 73-79. [CrossRef]

7. Vasilieva, E.A.; Samarkina, D.A.; Gaynanova, G.A.; Lukashenko, S.S.; Gabdrakhmanov, D.R.; Zakharov, V.M.; Vasileva, L.A.; Zakharova, L.Y. Self-assembly of the mixed systems based on cationic surfactants and different types of polyanions: The influence of structural and concentration factors. J. Mol. Liq. 2018, 272, 892-901. [CrossRef]

8. Tseng, H.-W.; Chen, P.-C.; Tsui, H.-W.; Wang, C.-H.; Hu, T.-Y.; Chen, L.-J. Effect of molecular weight of poly(acrylic acid) on the interaction of oppositely charged ionic surfactant-polyelectrolyte mixtures. J. Taiwan Inst. Chem. Eng. 2018, 92, 50-57. [CrossRef]

9. Asadov, Z.H.; Nasibova, S.M.; Ahmadova, G.A.; Zubkov, F.I.; Rahimov, R.A. Head-group effect of surfactants of cationic type in interaction with propoxylated sodium salt of polyacrylic acid in aqueous solution. Colloids Surf. A. 2017, 527, 95-100. [CrossRef]

10. Yan, P.; Jin, C.; Wang, C.; Ye, J.P.; Xiao, J.X. Effect of surfactant head group size on polyelectrolyte-surfactant interactions: Steady-state and time-resolved fluorescence study. J. Colloid Interface Sci. 2005, 282, 188-192. [CrossRef]

11. Langevin, D. Complexation of oppositely charged polyelectrolytes and surfactants in aqueous solutions. A review. Adv. Colloid Interface Sci. 2009, 147-148, 170-177. [CrossRef] 
12. Wang, C.; Tam, K.C. Interaction between polyelectrolyte and oppositely charged surfactant: Effect of charge density. J. Phys. Chem. B. 2004, 108, 8976-8982. [CrossRef]

13. Schulze-Zachau, F.; Braunschweig, B. $C_{n}$ TAB/polystyrene sulfonate mixtures at air-water interfaces: Effects of alkyl chain length on surface activity and charging state. Phys. Chem. Chem. Phys. 2019, 21,7847-7856. [CrossRef] [PubMed]

14. Tripathy, S.K.; Kumar, J.; Nalwa, H.S. Handbook of Polyelectrolytes and Their Applications; American Scientific Publishers: Stevenson Ranch, CA, USA, 2002.

15. Ray, D.; Das, B. Micellization of ionic liquid surfactants induced by sodium polystyrenesulfonate in aqueous solutions. J. Solut. Chem. 2019, 48, 1576-1590. [CrossRef]

16. Koolivand-Salooki, M.; Javadi, A.; Bahramian, A.; Abdollahi, M. Dynamic interfacial properties and foamability of polyelectrolytesurfactant mixtures. Colloids Surf. A 2019, 562, 345-353. [CrossRef]

17. Gabdrakhmanov, D.R.; Valeeva, F.G.; Samarkina, D.A.; Lukashenko, S.S.; Mirgorodskaya, A.B.; Zakharova, L.Y. The first representative of cationic amphiphiles bearing three unsaturated moieties: Self-assembly and interaction with polypeptide. Colloids Surf. A. 2018, 558, 463-469. [CrossRef]

18. Jain, N.; Trabelsi, S.; Guillot, S.; McLoughlin, D.; Langevin, D.; Letellier, P.; Turmine, M. Citical aggregation concentration in mixed solutions of anionic polyelectrolytes and cationic surfactants. Langmuir 2004, 20, 8496-8503. [CrossRef]

19. Taylor, D.J.F.; Thomas, R.K.; Li, P.X. Adsorption of oppositely charged polyelectrolyte/surfactant mixtures. neutron reflection from alkyl trimethylammonium bromides and sodium poly(styrenesulfonate) at the air/water interface: The effect of surfactant chain length. Langmuir 2003, 19, 3712-3719. [CrossRef]

20. Kuznetsova, D.A.; Gabdrakhmanov, D.R.; Vasilieva, E.A.; Lukashenko, S.S.; Ahtamyanova, L.R.; Siraev, I.S.; Zakharova, L.Y. Supramolecular catalytic systems based on a cationic amphiphile and sodium polystyrene sulfonate for decomposition of organophosphorus pollutants. Russ. J. Org. Chem. 2019, 55, 11-16. [CrossRef]

21. Zhang, Y.; Chan, H.F.; Leong, K.W. Advanced materials and processing for drug delivery: The past and the future. Adv. Drug Delivery Rev. 2013, 65, 104-120. [CrossRef] [PubMed]

22. Kuznetsova, D.A.; Gabdrakhmanov, D.R.; Lukashenko, S.S.; Faizullin, D.A.; Zuev, Y.F.; Nizameev, I.R.; Kadirov, M.K.; Kuznetsov, D.M.; Zakharova, L.Y. Interaction of bovine serum albumin with cationic imidazoliumcontaining amphiphiles bearing urethane fragment: Effect of hydrophobic tail length. J. Mol. Liq. 2020, 307, 113001. [CrossRef]

23. Samarkina, D.A.; Gabdrakhmanov, D.R.; Lukashenko, S.S.; Nizameev, I.R.; Kadirov, M.K.; Zakharova, L.Y. Homologous series of amphiphiles bearing imidazolium head group: Complexation with bovine serum albumin. J. Mol. Liq. 2019, 275, 232-240. [CrossRef]

24. Kim, H.J.; Kim, A.; Miyata, K.; Kataoka, K. Recent progress in development of siRNA delivery vehicles for cancer therapy. Adv. Drug Deliv. Rev. 2016, 104, 61-77. [CrossRef] [PubMed]

25. Wittrup, A.; Lieberman, J. Knocking down disease: A progress report on siRNA therapeutics. Nat. Rev. Genet. 2015, 16, 543-552. [CrossRef] [PubMed]

26. Wettig, S.D.; Verrall, R.E.; Foldvari, M. Gemini surfactants: A new family of building blocks for non-viral gene delivery systems. Curr. Gene Ther. 2008, 8, 9-23. [CrossRef] [PubMed]

27. Xu, L.; Feng, L.; Dong, R.; Hao, J.; Dong, S. Transfection efficiency of DNA enhanced by association with salt-free catanionic vesicles. Biomacromolecules 2013, 14, 2781-2789. [CrossRef] [PubMed]

28. Andrzejewska, W.; Wilkowska, M.; Peplinska, B.; Skrzypczak, A.; Kozak, M. Structural characterization of transfection nanosystems based on tricationic surfactants and short double stranded oligonucleotides. Biochem. Biophys. Res. Commun. 2019, 518, 706-711. [CrossRef]

29. Szala, S. Terapia Genowa; Wydawnictwo Naukowe PWN: Warsaw, Poland, 2003.

30. Leitner, S.; Grijalvo, S.; Solans, C.; Eritja, R.; García-Celma, M.J.; Calderó, G. Ethylcellulose nanoparticles as a new "in vitro" transfection tool for antisense oligonucleotide delivery. Carbohydr. Polym. 2020, 229, 115451. [CrossRef]

31. López-López, M.; López-Cornejo, P.; Martín, V.I.; Ostos, F.J.; Checa-Rodríguez, C.; Prados-Carvajal, R.; Lebrón, J.A.; Huertas, P.; Moyá, M.L. Importance of hydrophobic interactions in the single-chained cationic surfactant-DNA complexation. J. Colloid Interface Sci. 2018, 521, 197-205. [CrossRef]

32. Limeresa, M.J.; Suñé-Poua, M.; Prieto-Sánchez, S.; Moreno-Castro, C.; Nusblat, A.D.; Hernández-Munain, C.; Castro, G.R.; Suñé, C.; Suñé-Negre, J.M.; Cuetsas, M.L. Development and characterization of an improved formulation of cholesteryl oleate-loaded cationic solid-lipid nanoparticles as an efficient non-viral gene delivery system. Colloids Surf. B. 2019, 184, 110533. [CrossRef]

33. Mashal, M.; Attia, N.; Soto-Sánchez, C.; Martínez-Navarrete, G.; Fernández, E.; Puras, G.; Pedraz, J.L. Non-viral vectors based on cationic niosomes as efficient gene delivery vehicles to central nervous system cells into the brain. Int. J. Pharm. 2018, 552, 48-55. [CrossRef]

34. Zhang, J.; Wang, Z.; Lin, W.; Chen, S. Gene transfection in complex media using PCBMAEE-PCBMA copolymer with both hydrolytic and zwitterionic blocks. Biomaterials 2014, 35, 7909-7918. [CrossRef]

35. Soni, S.; Sarkar, S.; Mirzadeh, N.; Selvakannan, P.; Bhargava, S. Self-assembled functional nanostructure of plasmid DNA with ionic liquid [Bmim] $\left.\mathrm{PF}_{6}\right]$ : Enhanced efficiency in bacterial gene transformation. Langmuir 2015, 31, 4722-4732. [CrossRef]

36. Huang, Q.; Ou, W.; Chen, H.; Feng, Z.; Wang, J.-Y.; Zhang, J.; Zhu, W.; Yu, X.-Q. Novel cationic lipids possessing protonated cyclen and imidazolium salt for gene delivery. Eur. J. Pharm. Biopharm. 2011, 78, 326-335. [CrossRef] [PubMed] 
37. Zhou, T.; Llizo, A.; Li, P.; Wang, C.; Guo, Y.; Ao, M.; Bai, L. High transfection efficiency of homogeneous DNA nanoparticles induced by imidazolium gemini surfactant as nonviral vector. J. Phys. Chem. C 2013, 117, 26573-26581. [CrossRef]

38. Zhou, T.; Xu, G.; Ao, M.; Yang, Y.; Wang, C. DNA compaction to multi-molecular DNA condensation induced by cationic imidazolium gemini surfactants. Colloids Surf. A. 2012, 414, 33-40. [CrossRef]

39. Manning, G.S. Limiting Laws and Counterion Condensation in Polyelectrolyte Solutions I. Colligative Properties. J. Chem. Phys. 1969, 51, 924-938. [CrossRef]

40. Yoshida, K.; Dubin, P.L. Complex formation between polyacrylic acid and cationic:nonionic mixed micelles: Effect of pH on electrostatic interaction and hydrogen bonding. Colloids Surf. A. 1999, 147, 161-167. [CrossRef]

41. Vasilieva, E.A.; Lukashenko, S.S.; Vasileva, L.A.; Pavlov, R.V.; Gaynanova, G.A.; Zakharova, L.Y. Aggregation behavior of the surfactant bearing pyrrolidinium head group in the presence of polyacrylic acid. Russ. Chem. Bull. 2019, 68, 341-346. [CrossRef]

42. Vasilieva, E.A.; Ibragimova, A.R.; Lukashenko, S.S.; Konovalov, A.I.; Zakharova, L.Y. Mixed self-assembly of polyacrylic acid and oppositely charged gemini surfactants differing in the structure of head group. Fluid Phase Equilib. 2014, 376, 172-180. [CrossRef]

43. Samarkina, D.A.; Gabdrakhmanov, D.R.; Lukashenko, S.S.; Khamatgalimov, A.R.; Zakharova, L.Y. Aggregation capacity and complexation properties of a system based on an imidazole-containing amphiphile and bovine serum albumin. Russ. J. Gen. Chem. 2017, 87, 2826-2831. [CrossRef]

44. Hunt, K.K.; Vorburger, S.A.; Swisher, S.G. Gene Therapy for Cancer; Humana Press: Totowa, NJ, USA, 2007.

45. Samarkina, D.A.; Gabdrakhmanov, D.R.; Lukashenko, S.S.; Khamatgalimov, A.R.; Kovalenko, V.I.; Zakharova, L.Y. Cationic amphiphiles bearing imidazole fragment: From aggregation properties to potential in biotechnologies. Colloids Surf. A. 2017, 529, 990-997. [CrossRef]

46. Salakhieva, D.; Shevchenko, V.; Németh, C.; Gyarmati, B.; Szilágyi, A.; Abdullin, T. Structure-biocompatibility and transfection activity relationships of cationic polyaspartamides with (dialkylamino)alkyl and alkyl or hydroxyalkyl side groups. Int. J. Pharm. 2017, 517, 234-246. [CrossRef]

47. Jumbri, K.; Ahmad, H.; Abdulmalek, E.; Basyaruddin, M.; Rahman, A. Binding energy and biophysical properties of ionic liquid-DNA complex: Understanding the role of hydrophobic interactions. J. Mol. Liq. 2016, 223, 1197-1203. [CrossRef]

48. Grigoriev, I.V.; Korobeynikov, V.A.; Cheresiz, S.V.; Pokrovskiy, A.G.; Zakharova, L.Y.; Voronin, M.A.; Lukashenko, S.S.; Konovalov, A.I.; Zuev, Y.F. Cationic gemini surfactants as new agents for plasmid DNA delivery into cells. Dokl. Biochem. Biophys. 2012, 445, 197-199. [CrossRef] [PubMed]

49. Kuznetsova, D.A.; Gabdrakhmanov, D.R.; Lukashenko, S.S.; Voloshina, A.D.; Sapunova, A.S.; Kashapov, R.R.; Zakharova, L.Y. Self-assembled systems based on novel hydroxyethylated imidazolium-containing amphiphiles: Interaction with DNA decamer, protein and lipid. Chem. Phys. Lipids. 2019, 223, 104791. [CrossRef]

50. Gabdrakhmanov, D.R.; Vasilieva, E.A.; Voronin, M.A.; Kuznetsova, D.A.; Valeeva, F.G.; Mirgorodskaya, A.B.; Lukashenko, S.S.; Zakharov, V.M.; Mukhitov, A.R.; Faizullin, D.A.; et al. Soft nanocontainers based on hydroxyethylated geminis: Role of spacer in self-assembling, solubilization, and complexation with oligonucleotide. J. Phys. Chem. C 2020, 124, 2178-2192. [CrossRef]

51. Kuznetsova, D.A.; Gabdrakhmanov, D.R.; Lukashenko, S.S.; Ahtamyanova, L.R.; Nizameev, I.R.; Kadirov, M.K.; Zakharova, L.Y. Novel hybrid liposomal formulations based on imidazolium-containing amphiphiles for drug encapsulation. Colloids Surf. $B$ 2019, 178, 352-357. [CrossRef] [PubMed]

52. Zakharova, L.; Voronin, M.; Semenov, V.; Gabdrakhmanov, D.; Syakaev, V.; Gogolev, Y.; Giniyatullin, R.; Lukashenko, S.; Reznik, V.; Latypov, S.; et al. Supramolecular systems based on novel mono- and dicationic pyrimidinic amphiphiles and oligonucleotides: A self-organization and complexation study. Chem. Phys. Chem. 2012, 13, 788-796. [CrossRef] [PubMed]

53. Gabdrakhmanov, D.; Samarkina, D.; Semenov, V.; Syakaev, V.; Giniyatullin, R.; Gogoleva, N.; Zakharova, L. Novel dicationic pyrimidinic surfactant: Self-assembly and DNA complexation. Colloids Surf. A 2015, 480, 113-121. [CrossRef]

54. Kuznetsova, D.A.; Gaynanova, G.A.; Vasileva, L.A.; Sibgatullina, G.V.; Samigullin, D.V.; Sapunova, A.S.; Voloshina, A.D.; Galkina, I.V.; Petrov, K.A.; Zakharova, L.Y. Mitochondria-targeted cationic liposomes modified with alkyltriphenylphosphonium bromides loaded with hydrophilic drugs: Preparation, cytotoxicity and colocalization assay. J. Mater. Chem. B 2019, 7, 7351-7362. [CrossRef] [PubMed]

55. Von Smoluchowski, M. Contribution to the theory of electro-osmosis and related phenomena. Bull. Int. Acad. Sci. Cracovie 1903, 3, 184-199.

56. Aguiar, J.; Carpena, P.; Molina-Bolívar, J.A.; Carnero Ruiz, C. On the determination of the critical micelle concentration by the pyrene 1:3 ratio method. J. Colloid Interface Sci. 2003, 258, 116-122. [CrossRef] 